www.nature.com/ejhg

\title{
Cystathionine $\beta$-synthase polymorphisms and hyperhomocysteinaemia: an association study
}

\author{
Karin JA Lievers ${ }^{1}$, Leo AJ Kluijtmans ${ }^{1}$, Sandra G Heil ${ }^{1}$, Godfried HJ Boers ${ }^{2}$, Petra Verhoef ${ }^{4}$, \\ Martin den Heijer ${ }^{3}$, Frans JM Trijbels ${ }^{1}$ and Henk J Blom*,1
}

${ }^{1}$ Laboratory of Pediatrics and Neurology, University Medical Center Nijmegen, The Netherlands; ${ }^{2}$ Department of Internal Medicine, University Medical Center Nijmegen, The Netherlands; ${ }^{3}$ Department of Internal Medicine, Division of Endocrinology, University Medical Center Nijmegen, The Netherlands; ${ }^{4}$ Wageningen Center for Food Sciences and Division of Human Nutrition and Epidemiology, Wageningen University, Wageningen, The Netherlands

Hyperhomocysteinaemia is generally accepted as an independent and graded risk factor for both arterial occlusive disease and venous thrombosis. The only way of homocysteine degradation is conversion to cysteine in the transsulfuration pathway in which the regulating step is catalysed by cystathionine $\beta$ synthase (CBS). Mild impairment of CBS function could therefore affect homocysteine concentration, in particular after methionine loading, and consequently cardiovascular disease (CVD) risk. We analysed two silent polymorphisms and one short tandem repeat in the CBS gene (ie 699C $\rightarrow T, 1080 \mathrm{C} \rightarrow \mathrm{T}$ and -5697 (GT) STR) as genetic markers potentially in linkage disequilibrium with a functional polymorphism. We assessed their association with fasting and post-methionine load homocysteine in 190 patients with arterial occlusive disease, and in 381 controls. No differences in CBS genotype frequencies between cases and controls were found, nor was a particular CBS genotype associated with an elevated risk of arterial occlusive disease. Although we did find a high rate of linkage disequilibrium between the two single nucleotide polymorphisms and the GT STR, none of the genotypes defined by the three CBS variants studied showed an association with elevated fasting, post-load or increase upon methionine loading homocysteine concentrations. In conclusion, we did not find any indication that genetic variation in the CBS gene is associated with increased homocysteine concentrations.

European Journal of Human Genetics (2003) 11, 23-29. doi:10.1038/sj.ejhg.5200899

Keywords: cystathionine $\beta$-synthase (CBS); homocysteine; polymorphism; cardiovascular disease; association study; linkage disequilibrium

\section{Introduction}

Established risk factors for cardiovascular disease (CVD) include elevated blood cholesterol, hypertension, diabetes mellitus and tobacco smoking. A modest elevation of plasma homocysteine concentration, commonly referred to as hyperhomocysteinemia, is generally, ${ }^{1,2}$ though not universally ${ }^{3,4}$ accepted as an independent and graded risk factor for both arterial occlusive diseases and venous thrombosis. ${ }^{5,6}$ Homocysteine, an intermediate sulfur amino acid in

*Correspondence: Dr HJ Blom, Laboratory of Pediatrics and Neurology, University Medical Center Nijmegen, PO Box 9101, $6500 \mathrm{HB}$, Nijmegen, The Netherlands. Tel: +31 24 3613469; Fax: +31 24 3618900;

E-mail: H.Blom@cukz.umcn.nl

Received 4 June 2002; revised 7 August 2002; accepted 26 August 2002 methionine metabolism, may either be irreversibly degraded to cysteine via cystathionine in the transsulfuration pathway or remethylated to methionine. The remethylation by methionine synthase requires 5-methyltetrahydrofolate for methyl donation and vitamin B12 for methyl transport, while the remethylation by betainehomocysteine-methyltransferase requires betaine as methyl donor. The regulating step in the transsulfuration pathway is catalysed by cystathionine $\beta$-synthase (CBS), a pyridoxal 5 '-phosphate-dependent enzyme. The inherited metabolic disorder CBS deficiency is acknowledged to be the most frequent cause of homocystinuria in humans. ${ }^{7}$

In 1985, Boers et al ${ }^{8}$ postulated heterozygosity for CBS deficiency as a major cause of hyperhomocysteinaemia in 
CVD patients. This was based on the decreased CBS activities they found in extracts of cultured fibroblasts of hyperhomocysteinaemic vascular disease patients and their increased post-methionine loading homocysteine concentrations, both resembling those of obligate heterozygotes for CBS deficiency. Similar results were described by Clarke et al. ${ }^{9}$ Both studies however, do not reconcile with an earlier observation by Mudd et al, ${ }^{10}$ who described a similar incidence of heart attacks or strokes in parents and grandparents of homocystinuric children compared with relatives of children with either new-mutation achondroplastic dwarfism or with impaired phenylalanine metabolism. Furthermore, the finding of decreased CBS activities in cultured fibroblasts from hyperhomocysteinaemic vascular disease patients in the range of obligate heterozygotes could not be reproduced by us, ${ }^{11,12}$ and still needs clarification. In addition to fasting homocysteine concentrations, also post-methionine load homocysteine concentrations were found to be correlated among family members of patients with hyperhomocysteinaemia and vascular disease. ${ }^{13-15}$ So, it can be concluded that hyperhomocysteinaemia is, at least partially, genetically based. Still, elevated post-methionine load homocysteine concentrations are associated with increased CVD risk, ${ }^{16-18}$ but its genetic determinants remain obscure.

Over 100 mutations have been described in the CBS gene in classical homocystinuria patients. ${ }^{19}$ A 68 bp insertion in exon 8, first reported as a causal mutation in an Italian patient, was found to be polymorphic and not to be associated with plasma homocysteine concentrations. ${ }^{20,21}$ No other potentially functional polymorphisms associated with elevated homocysteine levels were detected in the CBS gene in the analyses of the genetic basis of homocystinuria. However, most studies performed thus far only examined the coding region of the CBS gene, leaving the non-coding regions unexplored.

Very recently, we described an inverse correlation between the number of tandem repeats defined by a $31 \mathrm{bp}$ VNTR (variable number of tandem repeats), ${ }^{22}$ and CBS enzyme activities in fibroblasts. ${ }^{23}$ Furthermore, a positive association was observed between the number of repeat units and post-methionine load plasma homocysteine concentrations. $^{23}$

Genetic association studies are widely used for the identification of candidate genes of complex, ie non-mendelian traits. $^{24}$ In such studies, the association is investigated between a phenotype and genomic markers close to or, preferably, within the gene of interest. Such a marker in itself is not necessarily functionally related to the phenotype but may be in linkage disequilibrium with a functional variant.

In the present study, we investigated the potential involvement of genetic variants in non-coding regions or of silent mutations in the CBS gene in hyperhomocysteinaemia and vascular disease, as possible markers which may be in linkage disequilibrium with a functional polymorphism. We analysed two silent single nucleotide polymorphisms $(699 \mathrm{C} \rightarrow \mathrm{T}, 1080 \mathrm{C} \rightarrow \mathrm{T})$ and a short tandem repeat (STR) $-5697(\mathrm{GT}),{ }^{22}$ in the CBS gene in 190 vascular disease patients and in 381 population-based controls. We report the allele frequencies and genotype distributions of these polymorphic variants in both study groups, and describe their association with fasting, post-methionine load and delta (ie increase upon methionine loading) plasma homocysteine concentrations. Also, the extent of linkage disequilibrium between the several CBS variants are calculated.

\section{Materials and methods}

\section{Study population}

We studied 190 patients with coronary, peripheral or cerebral vascular disease; a total of 130 cases were recruited from a cohort of patients who underwent coronary angiography in the Zuiderziekenhuis Hospital in Rotterdam, The Netherlands. ${ }^{18}$ Reasons for angiography were myocardial infarction or angina pectoris and cases were defined as those having $\geqslant 90 \%$ occlusion in one and $\geqslant 40 \%$ occlusion in one additional coronary artery. The other 60 patients had documented premature cardiovascular disease of which 10 patients had suffered from myocardial infarction, 32 from cerebral arterial occlusive disease and 18 from peripheral arterial occlusive disease. ${ }^{12}$

The control group consisted of 381 controls, of whom 101 were included from the general population in Rotterdam and comprised subjects with no history of cardiovascular disease $^{18}$ and 280 were recruited from a general practice in The Hague, The Netherlands to take part in a health survey. ${ }^{25}$

\section{Biochemical parameters}

After an overnight fast, blood was collected in EDTA tubes for measurement of fasting total homocysteine. The EDTA-blood samples were placed on ice immediately, and centrifuged for $10 \mathrm{~min}$ at $3000 \mathrm{~g}$ with minimal delay. All individuals were subjected to a standardised methionine loading test. ${ }^{26}$ Briefly, L-methionine $(0.1 \mathrm{~g} / \mathrm{kg}$ body weight $)$ was dissolved in $200 \mathrm{~mL}$ orange juice and administered orally. All study subjects received a standardised low protein breakfast and luncheon, and were asked not to consume any milk-containing beverages. After $6 \mathrm{~h}$, another blood sample was drawn for assessment of the post-methionine load homocysteine concentration. Total homocysteine was measured in plasma using a high-performance liquid chromatography (HPLC) procedure, with reverse phase separation and fluorescence detection, as described by $\mathrm{Te}$ Poele-Pothoff et al. ${ }^{27}$ All homocysteine measurements were conducted at the University Medical Center Nijmegen, The Netherlands, and fasting and post-load plasma homocysteine levels were obtained from 555 and 525 individuals, respectively. 
Detection of CBS polymorphisms

Genomic DNA was isolated from buffy coats of EDTA blood by a standard method, ${ }^{28}$ and stored at $4^{\circ} \mathrm{C}$ until analysis. Genomic DNA was available from 561 individuals.

\section{$699 \mathrm{C} \rightarrow \mathrm{T}$ transition}

This polymorphism does not create a restriction enzyme recognition site, and was therefore analysed by Primer Introduced Restriction Analysis. A mutagenic sense oligonucleotide (5'-CAGCAACCCCCTGGCTCAGT-3') introduces a RsaI site in the 699C allele and together with an antisense oligonucleotide (5'-TTATCGTTTGTGTCCCGTACCG-3') a genomic DNA fragment of $287 \mathrm{bp}$ was amplified using approximately $100 \mathrm{ng}$ genomic DNA and $100 \mathrm{ng}$ of both oligonucleotides in a standard PCR buffer $(10 \mathrm{~mm}$ Tris$\mathrm{HCl}$, pH 8.3; $50 \mathrm{mM} \mathrm{KCl)} \mathrm{containing} 2 \mathrm{mM} \mathrm{MgCl}_{2}$ and $200 \mu \mathrm{M}$ dNTPs. PCR parameters were as follows: 3 min initial denaturation at $92^{\circ} \mathrm{C}$, followed by 35 cycles of $92^{\circ} \mathrm{C} / 60 \mathrm{~s}$, $64^{\circ} \mathrm{C} / 60 \mathrm{~s}, 72^{\circ} \mathrm{C} / 30 \mathrm{~s}$, and a final extension of $7 \mathrm{~min}$ at $72^{\circ} \mathrm{C}$. After digestion with $R s a \mathrm{I}$ and resolution of the fragments on a $20 \%$ polyacrylamide gel, the 699 CC genotype results in fragments of $171,92,20$ and $4 \mathrm{bp}$, whereas the 699 TT genotype shows fragments of 171,112 and $4 \mathrm{bp}$.

\section{$1080 \mathrm{C} \rightarrow \mathrm{T}$ transition}

A genomic DNA fragment of $88 \mathrm{bp}$ was amplified by PCR using both $100 \mathrm{ng}$ forward (5'-CTGGCAGCACGGTGGCGG-3') and $100 \mathrm{ng}$ reverse oligonucleotides (5'-CGCACTGAGTCGGGCAGAATG-3'), and approximately $100 \mathrm{ng}$ genomic DNA in a standard PCR buffer (10 mM Tris-HCl, $\mathrm{pH} 8.3$; $50 \mathrm{~mm} \mathrm{KCl}$ ) containing $2 \mathrm{mM} \mathrm{MgCl}_{2}$ and $200 \mu \mathrm{M}$ dNTPs. All samples were cycled 35 times: $1 \mathrm{~min} / 92^{\circ} \mathrm{C}$ denaturation, $1 \mathrm{~min} / 55^{\circ} \mathrm{C}$ annealing, $30 \mathrm{~s} / 72^{\circ} \mathrm{C}$ extension, preceded by an initial denaturation of $3 \mathrm{~min} / 92^{\circ} \mathrm{C}$ and followed by a final extension of $7 \mathrm{~min} / 72^{\circ} \mathrm{C}$. The PCR fragment was analysed by $B s t$ UI restriction enzyme analysis followed by separation on a $2 \%$ agarose gel. The 1080 TT genotype results in an uncut fragment of $88 \mathrm{bp}$, the 1080 CC genotype in two fragments of 55 and $33 \mathrm{bp}$, whereas the heterozygous CT genotype is displayed by three fragments $(88,55$, and $33 \mathrm{bp})$.

\section{-5697 (GT) STR}

A PCR was performed with a $5^{\prime} \mathrm{FAM}$ labelled forward primer (5'-GAGCTGAAATCACACCACT-3') and a reverse primer (5'GTTTTTACTACATTTGCTCCC-3') in a standard PCR buffer containing $2 \mathrm{mM} \mathrm{MgCl}_{2}$ and using an annealing temperature of $58^{\circ} \mathrm{C}$. The $193-211 \mathrm{bp}$ fluorescently labelled PCR products were separated on a $4 \%$ denaturating polyacrylamide gel using the ABI Prism 377, according to the manufacturer's recommendations. Data-analysis was performed using the Genescan and Genotyper Software (Perkin Elmer).

\section{Statistical analysis}

Plasma homocysteine concentrations showed positive skewness, therefore log-transformed homocysteine levels were used in all analyses. Differences in genotype distributions, allele frequencies and gender were assessed by Pearson's $\chi^{2}$ analysis. Differences in continuous variables between cases and controls were assessed by Student's $t$-test, adjusted for age and gender by means of linear regression analysis. One-way analysis of variance (ANOVA) was used to assess the differences of continuous variables between different genotypes, followed by Bonferroni-corrected $t$-tests. Odds ratios (OR) and 95\% confidence intervals (95\% CI) as estimates of the relative risk for arterial occlusive disease for the different CBS genotypes, were calculated with logistic regression analysis. We also investigated the association between these three genetic variants and the $31 \mathrm{bp}$ VNTR, of which alleles 19 and 21 were shown to be associated with increased post-methionine load homocysteine concentrations. $^{23}$ The haplotype frequencies and linkage disequilibria were estimated by the $\mathrm{EH}$ program. ${ }^{29} \mathrm{D}^{\prime}$ reflects the extent of the linkage disequilibrium, which is reported as the ratio between the actual value of $\mathrm{D}$ (ie the departure from linkage disequilibrium) and the maximum value it can have for the given allele frequencies. The sign in front of the coefficients indicates whether the rare alleles are associated $(+)$ or the rare allele is associated with the frequent allele $(-)$. All $P$-values reported are two-tailed, and statistical significance was accepted at $P<0.05$.

\section{Results}

Table 1 depicts age, gender, and total plasma homocysteine concentrations (ie fasting, post methionine load, and net increase upon methionine loading) of cases and controls. Age, expressed as the geometric mean, and the percentage males did not differ between the two groups. A higher fasting homocysteine $(+7.5 \% ; P=0.011)$ and post-methionine loading homocysteine concentration $(+5.6 \% ; P=0.045)$ was seen in cases compared with controls. Cases and controls showed a comparable net increase upon methionine loading (ie post-load minus fasting homocysteine concentration).

Both $699 \mathrm{C} \rightarrow \mathrm{T}, 1080 \mathrm{C} \rightarrow \mathrm{T}$ as well as the GT STR genotype distributions were in Hardy-Weinberg equilibrium (data not shown). Genotype distributions for each of the three CBS polymorphisms were similar in cases and controls (Table 2 , left side). The allele frequency of the 699T allele was 0.37 and 0.35 in patients and controls, respectively $\left(\chi^{2}=0.30, P=0.58\right)$; the 1080 T allele had an allele frequency of 0.32 in patients and of 0.37 in controls $\left(\chi^{2}=2.89\right.$, $P=0.09$ ). In our study population, we identified 10 different alleles defined by the highly polymorphic GT STR (which were named after the number of repeat units) that led to the observation of 22 different genotype combinations (Table 2).

CBS genotypes were investigated as risk factors for arterial occlusive disease. The differences in CBS genotype frequencies between the case and control group were not statistically significant (Table 2). Odds ratios for the 699TT 
Table 1 Characteristics and plasma homocysteine concentration (tHcy) in cases and controls

\begin{tabular}{llll}
\hline & $\begin{array}{l}\text { Cases } \\
(\mathrm{n}=190)\end{array}$ & $\begin{array}{l}\text { Controls } \\
(\mathrm{n}=381)\end{array}$ & $p^{a}$ \\
\hline Age (years) & $49.0 \pm 10.2$ & $50.8 \pm 11.9$ & 0.11 \\
Gender $\%$ male) & 75.3 & 74.3 & $0.80^{\mathrm{b}}$ \\
Fasting tHcy $(\mu \mathrm{mol} / \mathrm{L})$ & $14.4(13.7-15.1)$ & $13.4(13.0-13.9)$ & $0.011^{\mathrm{c}}$ \\
Postload tHcy $(\mu \mathrm{mol} / \mathrm{L})_{\text {Postload increase }^{\mathrm{d}}(\mu \mathrm{mol} / \mathrm{L})}^{41.3(39.4-43.3)}$ & $26.1(38.0-40.3)$ & $0.045^{\mathrm{c}}$ \\
\hline
\end{tabular}

Age is expressed as mean \pm SD and thcy as geometric means $(95 \% \mathrm{Cl}) .{ }^{\text {a }}$ Student's $t$-test. ${ }^{\mathrm{b}}$ Pearson $\chi^{2}$ test. ${ }^{\mathrm{c}}$ Adjusted for age and gender. ${ }^{\mathrm{d}}$ Increase upon methionine loading (ie postload minus fasting thcy).

Table 2 CBS genotype distribution in cases and controls and the relationship between plasma homocysteine concentration (tHcy) and CBS genotypes (patients and controls combined)

\begin{tabular}{|c|c|c|c|c|c|}
\hline $\begin{array}{l}\text { CBS } \\
\text { genotype }\end{array}$ & $\begin{array}{l}\text { Patients } \\
N(\%)\end{array}$ & $\begin{array}{l}\text { Controls } \\
N(\%)\end{array}$ & $\begin{array}{l}\text { Fasting } \\
\text { tHcy } \\
\mu \mathrm{mol} / \mathrm{L}\end{array}$ & $\begin{array}{l}\text { Postload } \\
\text { tHcy } \\
\mu \mathrm{mol} / \mathrm{L}\end{array}$ & $\Delta t H c y^{a}$ \\
\hline 699CC & $76(40.0)$ & $156(42.9)$ & 13.9 & 40.0 & 25.1 \\
\hline \multirow[t]{2}{*}{ 699Tा } & $27(14.2)$ & $50(13.7)$ & 14.2 & 40.0 & 25.1 \\
\hline & \multicolumn{2}{|c|}{$\chi^{2}=0.41 ; P=0.81$} & $P=0.60^{\mathrm{b}}$ & $P=0.92^{\mathrm{b}}$ & $P=0.91^{b}$ \\
\hline $1080 \mathrm{CC}$ & $93(49.2)$ & $150(40.4)$ & 14.0 & 40.6 & 25.9 \\
\hline $1080 \pi$ & \multicolumn{2}{|c|}{$\chi^{2}=3.98 ; P=0.14$} & $P=0.58^{b}$ & $P=0.38^{\mathrm{b}}$ & $P=0.44^{b}$ \\
\hline \multicolumn{6}{|l|}{ GT STR } \\
\hline $14-14$ & $1(0.5)$ & $1(0.3)$ & 20.1 & 44.3 & 24.2 \\
\hline $11-16$ & 0 & $1(0.3)$ & 11.4 & 31.8 & 20.5 \\
\hline $12-16$ & $1(0.5)$ & 0 & 11.6 & - & - \\
\hline $13-16$ & 0 & $1(0.3)$ & 9.6 & 24.3 & 14.8 \\
\hline $14-16$ & $9(4.8)$ & $33(9.6)$ & 14.3 & 40.6 & 26.1 \\
\hline $14-18$ & $1(0.5)$ & $4(1.2)$ & 13.1 & 37.5 & 23.6 \\
\hline $15-18$ & $1(0.5)$ & $1(0.3)$ & 13.4 & 47.6 & 33.5 \\
\hline $16-18$ & $14(7.5)$ & $25(7.3)$ & 13.7 & 38.7 & 24.7 \\
\hline $17-18$ & $2(1.1)$ & $8(2.3)$ & 15.3 & 38.1 & 22.5 \\
\hline $18-18$ & $2(1.1)$ & $1(0.3)$ & 11.6 & 34.3 & 22.6 \\
\hline $14-19$ & $1(0.5)$ & $2(0.6)$ & 13.6 & 45.3 & 30.5 \\
\hline 16-19 & $11(5.9)$ & $16(4.7)$ & 15.1 & 39.4 & 20.6 \\
\hline $17-19$ & $5(2.7)$ & $3(0.9)$ & 13.2 & 44.8 & 30.5 \\
\hline 18-19 & 0 & $1(0.3)$ & 12.8 & 38.5 & 25.8 \\
\hline $19-19$ & 0 & $1(0.3)$ & 7.8 & 20.7 & 12.8 \\
\hline $16-20$ & $1(0.5)$ & 0 & 18.9 & 46.1 & 27.0 \\
\hline \multirow{2}{*}{$17-20$} & \multirow{2}{*}{\multicolumn{2}{|c|}{$\chi^{2}=17.74 ; P=0.67$}} & 13.0 & 38.2 & 25.0 \\
\hline & & & $P=0.42^{b}$ & $P=0.78^{b}$ & $P=0.73^{b}$ \\
\hline
\end{tabular}

thcy expressed as geometric means $(95 \% \mathrm{Cl}) .{ }^{\mathrm{a}} \mathrm{Net}$ increase upon methionine loading (ie postload minus fasting tHcy). ${ }^{\mathrm{b}} \mathrm{ANOVA}$ on log transformed data.

and 699CT genotype, with the 699CC genotype as reference category, were 1.07 (95\% CI: $0.81-1.40)$ and 1.12 (95\% CI: $0.77-1.64)$ respectively. Odds ratios for the 1080TT and 1080CT genotype, with 1080CC as reference category, were 1.07 (95\% CI: $0.89-1.52$ ) and 0.94 (95\% CI: $0.54-1.62$ ) respectively.

In addition, the association between CBS genotypes and fasting and post-load plasma homocysteine concentrations was studied (Table 2, right side). We combined cases and controls to increase statistical power, since associations between CBS genotypes and plasma homocysteine did not differ between cases and controls (all $P$-values $>0.14$ ). For the $699 \mathrm{C} \rightarrow \mathrm{T}$ polymorphism no differences in fasting, post-load or delta homocysteine concentrations were observed between the three genotypes (Table 2). Furthermore, none of the genotypes defined by the $1080 \mathrm{C} \rightarrow \mathrm{T}$ 
polymorphism showed an association with elevated fasting, post-load or delta homocysteine concentration (Table 2). The different GT STR genotypes were also not associated with a change in plasma homocysteine concentrations (Table 2). We also investigated the association between

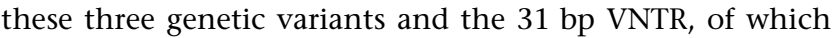
alleles 19 and 21 were shown to be associated with increased post-methionine load homocysteine concentrations. ${ }^{23}$ The positive association between alleles 19 and 21 and post-load homocysteine concentrations was however not reflected in one of the genotypes defined by the three variants studied here. We examined whether alleles 19 and 21 were located on particular haplotypes, but found out that this was not the case; six different haplotypes were observed containing allele 19, and three containing allele 21 (Table 3).

Linkage disequilibria were calculated between the $699 \mathrm{C} \rightarrow \mathrm{T}, 1080 \mathrm{C} \rightarrow \mathrm{T}$ and the GT STR and all were found to be highly significant $(P<0.001$; data not shown). All pairwise linkage disequilibria between the different CBS alleles are depicted in Table 4.

\section{Discussion}

In the present study, we investigated the potential involvement of variants in non-coding regions or silent mutations

Table 3 Haplotypes of the CBS 31 bp VNTR alleles 19 and 21 and their relative frequencies

\begin{tabular}{|c|c|c|c|c|c|}
\hline \multirow[b]{2}{*}{ Haplotype } & \multicolumn{4}{|c|}{ Polymorphisms } & \multirow{2}{*}{$\begin{array}{l}\text { Relative } \\
\text { frequency }\end{array}$} \\
\hline & $31 b p$ VNTR & GTSTR & $699 C \rightarrow T$ & $1080 \mathrm{C} \rightarrow T$ & \\
\hline$A$ & 19 & 15 & $\mathrm{~T}$ & C & 0.036 \\
\hline$B$ & 19 & 16 & C & C & 0.074 \\
\hline C & 19 & 16 & C & $\mathrm{T}$ & 0.036 \\
\hline $\mathrm{D}$ & 19 & 16 & $\mathrm{~T}$ & C & 0.448 \\
\hline $\mathrm{E}$ & 19 & 17 & C & $\mathrm{T}$ & 0.036 \\
\hline $\mathrm{F}$ & 19 & 17 & $\mathrm{~T}$ & C & 0.085 \\
\hline G & 21 & 16 & C & C & 0.190 \\
\hline $\mathrm{H}$ & 21 & 16 & $\mathrm{~T}$ & C & 0.038 \\
\hline I & 21 & 17 & C & C & 0.058 \\
\hline
\end{tabular}

Table 4 Linkage disequilibrium coefficients $\left(D^{\prime}\right)$ between different alleles of CBS polymorphisms. The sign in front of the coefficients indicates whether the rare alleles are associated (+) or whether the rare allele is associated with the frequent allele $(-)$

\begin{tabular}{llll}
\hline Polymorphism & Allele & $699 \mathrm{C} \rightarrow T$ & $1080 \mathrm{C} \rightarrow T$ \\
\hline $1080 \mathrm{C} \rightarrow \mathrm{T}$ & & -0.75 & - \\
$-5697(\mathrm{GT}) \mathrm{STR}$ & 14 & 0.71 & -0.80 \\
& 15 & 0.25 & -0.35 \\
& 16 & 0.25 & -0.08 \\
& 17 & -0.35 & 0.52 \\
& 18 & -0.47 & 0.67 \\
& 19 & -0.32 & -0.36 \\
\hline
\end{tabular}

in the CBS gene by analysing the $699 \mathrm{C} \rightarrow \mathrm{T}$ and $1080 \mathrm{C} \rightarrow \mathrm{T}$ variants and a GT STR, which is located in the promotor region, as markers of possible genetic CBS defects contributing to hyperhomocysteinaemia and to the risk of arterial occlusive disease. No differences in genotype distributions or allele frequencies were found between cases and controls, indicating that no particular CBS genotype is over-represented in arterial occlusive disease patients compared with controls. We investigated the associations between CBS genotypes and plasma homocysteine concentrations, especially after methionine loading. The two silent mutations as well as the GT STR did not show an association with homocysteine concentrations, neither fasting, nor postload, nor on the increase upon methionine loading.

Besides fasting plasma homocysteine concentrations, ${ }^{1,18}$ also post-methionine load homocysteine concentrations have been associated with an increased CVD risk. ${ }^{16,18,30}$ Verhoef et $a l^{18}$ calculated that the risk of coronary artery disease increased with $20 \%$ for each $12 \mu \mathrm{mol} / \mathrm{L}$ increase in post-load homocysteine levels. Graham et al ${ }^{31}$ reported a relative risk for vascular disease of 1.5 for a subject with a post-load homocysteine level above the 80th percentile of controls. Since methionine loading particularly promotes the transsulfuration of homocysteine into cysteine, in which CBS is the regulating enzyme, it has been postulated that hyperhomocysteinaemia after methionine loading reflects the involvement of suboptimal CBS function. ${ }^{32}$ Several studies excluded the involvement of heterozygosity for CBS deficiency in hyperhomocysteinaemia and premature vascular disease, ${ }^{12,33,34}$ but the results of these studies do not exclude an involvement of a mildly impaired CBS function. No potentially functional polymorphisms associated with hyperhomocysteinaemia after methionine loading were detected in the CBS gene in the analyses of the genetic basis of homocystinuria. However, most studies performed thus far only examined the coding region of the CBS gene, leaving the non-coding regions unexplored. The effect of a potential functional polymorphism may be reflected in other, non-functional, polymorphisms, in case they are in linkage disequilibrium.

Recently, Kruger et $a l^{35}$ calculated odds ratios of the 699TT and 1080CC genotypes versus the other two genotypes defined by each variant on the risk of coronary artery disease and found decreased risks, ie protective effects. However, individuals with the 699TT or 1080CC genotype had similar fasting homocysteine concentrations as the other genotypes and, unfortunately, no post-load homocysteine concentrations were available. They postulated that the 699T and 1080T alleles, may be linked to other yet unidentified functional polymorphisms in the CBS gene. These results were similar to those of De Stefano et $a l^{36}$ who also did not find an effect of both CBS $699 \mathrm{C} \rightarrow \mathrm{T}$ and the $1080 \mathrm{C} \rightarrow \mathrm{T}$ CBS variants on fasting homocysteine concentrations. They did not examine the association between the CBS variants and post-methionine load homo- 
leading to elevated homocysteine concentrations and increased CVD risk was found.

decreased post-methionine load homocysteine concentrations in individuals who were heterozygous or homozygous for the 699T allele compared with the 699CC subjects. This association became more significant when individuals carrying the 844ins68 and the 1080T allele were excluded. With regard to the $1080 \mathrm{C} \rightarrow \mathrm{T}$ polymorphism, the 1080T allele was associated with lower post-methionine load homocysteine levels only when individuals carrying the 844ins68 and the 699T allele were excluded from the analysis. They also speculated that the $699 \mathrm{C} \rightarrow \mathrm{T}$ and $1080 \mathrm{C} \rightarrow \mathrm{T}$ CBS variants may be in linkage disequilibrium with regulatory elements that upregulate CBS gene transcription. ${ }^{37}$ In the current study however, the two silent polymorphisms as well as the GT STR did not show any association with homocysteine concentrations, neither fasting, nor post-load, nor on the increase upon methionine loading. Both etiologic and genetic heterogeneity may play an important role in genetic association studies. Since the populations used in the different studies may have a different background, it is possible that the actual range of etiologies vary across samples. Allele frequencies of the $699 \mathrm{C} \rightarrow \mathrm{T}$ and $1080 \mathrm{C} \rightarrow \mathrm{T}$ polymorphisms were comparable between the three studies published earlier $^{35-37}$ and the present one, ranging from 31.8 to $39.4 \%$ for the $699 \mathrm{~T}$ allele and from 32.4 to $35.5 \%$ for the 1080T allele.

We also investigated the association between these three genetic variants and the $31 \mathrm{bp}$ VNTR, of which the alleles containing 19 and 21 repeat units were shown to be associated with increased post-methionine load homocysteine concentrations. $^{23}$ However, this positive association between alleles 19 and 21 and post-load homocysteine concentrations was not reflected in one of the genotypes defined by the three variants studied here. One explanation is that alleles 19 and 21 are rare (allele frequencies of 10.5 and $2.7 \%$, respectively) and are therefore not picked up by a genetic association analysis described here. Furthermore, we observed that alleles 19 and 21 were both not located on one particular haplotype, but that different haplotypes were observed containing allele 19 , which was also the case for allele 21 (Table 3).

In the present study, we detected strong linkage disequilibria between the CBS variants studied. For each pair of alleles, defined by the three CBS variants, linkage disequilibrium coefficients $\left(\mathrm{D}^{\prime}\right)$ were calculated (Table 4$)$. $\mathrm{D}^{\prime}$ between the $699 \mathrm{C} \rightarrow \mathrm{T}$ and the $1080 \mathrm{C} \rightarrow \mathrm{T}$ polymorphisms of -0.75 in our study is similar to that calculated by De Stephano $e \mathrm{al}^{36}$ of -0.83 in almost 800 subjects recruited from 11 European countries.

In conclusion, we did not find any genotype, defined by the three CBS variants studied here, associated with elevated homocysteine concentrations. Although we observed strong linkage between these three polymorphisms, no evidence for a common CBS polymorphism

\section{Acknowledgements}

This study was, in part, supported by grants 93.176 and 97.071 from the Netherlands Heart Foundation. Dr Leo AJ Kluijtmans is a post-doctoral fellow of the Netherlands Heart Foundation (D99.023) and Dr Henk J Blom is an Established Investigator of the Netherlands Heart Foundation (D97.021).

\section{References}

1 Wald NJ, Watt HC, Law MR, Weir DG, McPartlin J, Scott JM: Homocysteine and ischemic heart disease: results of a prospective study with implications regarding prevention. Arch Intern Med 1998; 158: 862-867.

2 Ueland PM, Refsum H, Beresford SA, Vollset SE: The controversy over homocysteine and cardiovascular risk. Am J Clin Nutr 2000; 72: $324-332$.

3 Folsom AR, Nieto FJ, McGovern PG et al: Prospective study of coronary heart disease incidence in relation to fasting total homocysteine, related genetic polymorphisms, and B vitamins: the Atherosclerosis Risk in Communities (ARIC) study. Circulation 1998; 98: 204-210.

4 Brattstrom L, Wilcken DE: Homocysteine and cardiovascular disease: cause or effect?. Am J Clin Nutr 2000; 72: 315-323.

5 Den Heijer M, Koster T, Blom HJ et al: Hyperhomocysteinemia as a risk factor for deep-vein thrombosis. $N$ Engl J Med 1996; 334: $759-762$.

6 Den Heijer M, Rosendaal FR, Blom HJ, Gerrits WB, Bos GM: Hyperhomocysteinemia and venous thrombosis: a meta-analysis. Thromb Haemost 1998; 80: 874-877.

7 Mudd SH, Levy HL, Skovby F (ed): Disorders of transsulfuration; in Scriver CS, Beaudet AL, Sly WS, Valle D (eds): The Metabolic and Molecular Basis of Inherited Disease. New York: McGraw-Hill, 1995; pp 1279-1327.

8 Boers GHJ, Smals AG, Trijbels JMF et al: Heterozygosity for homocystinuria in premature peripheral and cerebral occlusive arterial disease. N Engl J Med 1985; 313: 709-715.

9 Clarke R, Daly L, Robinson K et al: Hyperhomocysteinemia: an independent risk factor for vascular disease. N Engl J Med 1991; 324: $1149-1155$.

10 Mudd SH, Havlik R, Levy HL, McKusick VA, Feinleib M: A study of cardiovascular risk in heterozygotes for homocystinuria. Am J Hum Genet 1981; 33: 883-893.

11 Engbersen AM, Franken DG, Boers GH, Stevens EM, Trijbels FJ, Blom HJ: Thermolabile 5,10-methylenetetrahydrofolate reductase as a cause of mild hyperhomocysteinemia. Am J Hum Genet 1995; 56: $142-150$.

12 Kluijtmans LA, van den Heuvel LP, Boers GH et al: Molecular genetic analysis in mild hyperhomocysteinemia: a common mutation in the methylenetetrahydrofolate reductase gene is a genetic risk factor for cardiovascular disease. Am J Hum Genet 1996; 58: 35 - 41 .

13 Genest JJ, McNamara JR, Upson B et al: Prevalence of familial hyperhomocyst(e)inemia in men with premature coronary artery disease. Arterioscler Thromb 1991; 11: 1129-1136.

$14 \mathrm{Wu} \mathrm{LL}, \mathrm{Wu}$ J, Hunt SC et al: Plasma homocyst(e)ine as a risk factor for early familial coronary artery disease. Clin Chem 1994; 40: $552-561$.

15 Franken DG, Boers GH, Blom HJ, Cruysberg JR, Trijbels FJ, Hamel BC: Prevalence of familial mild hyperhomocysteinemia. Atherosclerosis 1996; 125: 71-80. 
16 Bostom AG, Jacques PF, Nadeau MR, Williams RR, Ellison RC, Selhub J: Post-methionine load hyperhomocysteinemia in persons with normal fasting total plasma homocysteine: initial results from the NHLBI Family Heart Study. Atherosclerosis 1995; 116: $147-151$

17 Kang SS, Wong PW: Genetic and nongenetic factors for moderate hyperhomocyst(e)inemia. Atherosclerosis 1996; 119: $135-138$.

18 Verhoef P, Kok FJ, Kruyssen DA et al: Plasma total homocysteine, B vitamins, and risk of coronary atherosclerosis. Arterioscler Thromb Vasc Biol 1997; 17: 989-995.

19 Kraus JP, Janosik M, Kozich V et al: Cystathionine beta-synthase mutations in homocystinuria. Hum Mutat 1999; 13: 362-375.

20 Tsai MY, Bignell M, Schwichtenberg K, Hanson NQ: High prevalence of a mutation in the cystathionine beta-synthase gene. Am I Hum Genet 1996; 59: 1262-1267.

21 Kluijtmans LA, Boers GH, Trijbels FJ, van Lith-Zanders HM, van den Heuvel LP, Blom HJ: A common 844INS68 insertion variant in the cystathionine beta-synthase gene. Biochem Mol Med 1997; 62: $23-25$.

22 Kraus JP, Oliveriusova J, Sokolova J et al: The human cystathionine beta-synthase (CBS) gene: complete sequence, alternative splicing, and polymorphisms. Genomics 1998; 52: 312-324.

23 Lievers KJ, Kluijtmans LA, Heil SG et al: A 31 bp VNTR in the cystathionine beta-synthase (CBS) gene is associated with reduced CBS activity and elevated post-load homocysteine levels. Eur J Hum Genet 2001; 9: 583-589.

24 Lander ES, Schork NJ: Genetic dissection of complex traits. Science 1994; 265: 2037-2048.

25 Den Heijer M, Blom HJ, Gerrits WB, Rosendaal FR, Haak HL, Wijermans PW, Bos GM: Is hyperhomocysteinaemia a risk factor for recurrent venous thrombosis?. Lancet 1995; 345: 882-885.

26 Boers GHJ, Smals AG, Trijbels JMF, Leermakers AI, Kloppenborg PW: Unique efficiency of methionine metabolism in premenopausal women may protect against vascular disease in the reproductive years. J Clin Invest 1983; 72: 1971-1976.

27 Te Poele-Pothoff MT, van den Berg M, Franken DG et al: Three different methods for the determination of total homocysteine in plasma. Ann Clin Biochem 1995; 32: 218-220.
28 Miller SA, Dykes DD, Polesky HF: A simple salting out procedure for extracting DNA from human nucleated cells. Nucleic Acids Res 1988; 16: 1215 .

29 Xie X, Ott J: Testing linkage disequilibrium between a disease gene and marker loci. Am J Hum Genet 1993; 53: 1107 (Abstract).

30 Verhoef P, Meleady R, Daly LE, Graham IM, Robinson K, Boers GH: Homocysteine, vitamin status and risk of vascular disease; effects of gender and menopausal status. European COMAC Group. Eur Heart J 1999; 20: 1234-1244.

31 Graham IM, Daly LE, Refsum HM et al: Plasma homocysteine as a risk factor for vascular disease. The European Concerted Action Project. JAMA 1997; 277: 1775-1781.

32 Finkelstein JD, Martin JJ: Methionine metabolism in mammals. Distribution of homocysteine between competing pathways. $J$ Biol Chem 1984; 259: 9508 -9513.

33 Kozich V, Kraus E, de Franchis R et al: Hyperhomocysteinemia in premature arterial disease: examination of cystathionine betasynthase alleles at the molecular level. Hum Mol Genet 1995; 4: $623-629$.

34 Gallagher PM, Meleady R, Shields DC et al: Homocysteine and risk of premature coronary heart disease. Evidence for a common gene mutation. Circulation 1996; 94: 2154-2158.

35 Kruger WD, Evans AA, Wang L et al: Polymorphisms in the CBS gene associated with decreased risk of coronary artery disease and increased responsiveness to total homocysteine lowering by folic acid. Mol Genet Metab 2000; 70: 53-60.

36 De Stefano V, Dekou V, Nicaud V et al: Linkage disequilibrium at the cystathionine beta synthase (CBS) locus and the association between genetic variation at the CBS locus and plasma levels of homocysteine. Ann Hum Genet 1998; 62: 481-490.

37 Aras O, Hanson NQ, Yang F, Tsai MY: Influence of $699 \mathrm{C} \rightarrow \mathrm{T}$ and $1080 \mathrm{C} \rightarrow \mathrm{T}$ polymorphisms of the cystathionine beta-synthase gene on plasma homocysteine levels. Clin Genet 2000; 58: 455 459 . 